\title{
Ley de Tramitación Electrónica y Cargas Procesales
}

\author{
Sentencia Corte Suprema de 13 de abril de 2020
}

\section{Digital procedural law and procedural burdens Supreme Court ruling april 13th 2020}

\author{
Jorge Sepúlveda GuZmán ${ }^{1}$
}

\begin{abstract}
RESUMEN
El siguiente comentario jurisprudencial analiza la sentencia dictada por la Corte Suprema el 13 de abril de 2020 que — de oficioanuló un fallo de la Corte de Apelaciones de Santiago. Lo anterior, declarando que la carga de consignar fondos suficientes para la tramitación de un recurso de casación en el fondo resulta inaplicable a las causas iniciadas con anterioridad a la entrada en vigencia de la Ley $\mathrm{N}^{\circ} 20.886$ sobre tramitación digital de los procedimientos judiciales, de tal forma que la sanción procesal consistente en tener por desistido dicho recurso es errónea. El presente comentario examina entonces las principales razones de esta sentencia, a la luz de otras decisiones adoptadas por la misma Corte Suprema y también su lógica interna al tenor de la historia de la ley, la doctrina y los cuerpos legales que regulan el novel sistema de tramitación digital chileno.
\end{abstract}

Palabras claves: tramitación electrónica, cargas procesales, disposiciones transitorias

\begin{abstract}
The following case law analysis addresses the Supreme Court ruling issued on April $13^{\text {th }}$, 2020, which invalidated a Santiago Court of Appeal decision, stating that the procedural burden consisting of allocating sufficient funds aimed to continue the proceedings associated to a cassation, does not apply to those cases filed before Law $\mathrm{N}^{\circ} 20.886$ entered into force, according to its transitory provisions and, as consequence, the abandonment of such recourse is against the law. The analysis also scrutinizes the main motivations raised by the Supreme Court ruling in the light of other judgments issued by the Supreme Court and examines its ratio decidendi under the legislative history, jurist opinions and the various bodies of law that governs the Chilean neophyte digital legal system.
\end{abstract}

Keywords: digital proceedings, procedural burdens, transitory provisions.

\footnotetext{
Abogado. Licenciado en Ciencias Jurídicas y Sociales, Facultad de Derecho Universidad de Chile. LL.M., University of Minnesota, Estados Unidos. Visiting Scholar, Duke University, Estados Unidos. Correo electrónico: jorge.sepulveda@cslegal.cl. Socio de la firma Correa Squella.
} 


\section{Introducción}

El 18 de diciembre de 2015 se publicó en el Diario Oficial la Ley № 20.886 o Ley de Tramitación Electrónica (LTE), que estableció la tramitación digital de los procedimientos judiciales y que entró progresivamente en vigencia durante el 2016. El propósito de esta modificación fue reemplazar los expedientes por carpetas electrónicas disponibles en la Oficina Judicial Virtual, de tal forma que tanto el ingreso de los escritos cuanto su consulta pudiera efectuarse desde cualquier dispositivo electrónico. En definitiva, como consta en la historia de la ley, este proyecto "busca agilizar los procesos, abaratar los costos de litigación, establecer una litigación responsable por parte de los abogados y generar una mayor cercanía de los justiciables con nuestro arcaico sistema" (Biblioteca del Congreso Nacional, 2015, p. 20). Así, a medida que la implementación de la LTE se afinó y los litigantes se adaptaron, se generó un significativo avance en la celeridad y seguridad de los juicios civiles.

Desde luego, el cambio no fue solo cosmético. La LTE también suprimió un conjunto de cargas procesales del sistema recursivo que bajo el sistema digital perdían justificación, por ejemplo: la deserción por no comparecer ante las Cortes, el desistimiento por no consignar fondos para las compulsas, la prescripción y la adhesión a la apelación en $1^{\text {a }}$ instancia (artículos 197, 200, 201, 211, 217, 776 y 779 del pretérito Código de Procedimiento Civil).

En paralelo, la LTE incorporó tres disposiciones transitorias orientadas a regular la entrada en vigencia de esta ley y a definir a qué procesos se aplicaba según su fecha de inicio. En principio, parecía claro que solo regía para las "causas nuevas" iniciadas con posterioridad a la LTE, de tal forma que solo aquellas se tramitarían digitalmente de forma obligatoria y que únicamente ellas quedaban eximidas de las derogadas sanciones. Pero como en el derecho no todo es blanco o negro, comenzaron a surgir "causas antiguas" en las que el recurrente no se hizo parte o no depositó las compulsas.

El asunto escaló hasta la Corte Suprema, que actuó de manera ambivalente. En algunas oportunidades estableció que estas cargas procesales continuaban en pie y, en otras, por contraste, que no resultaban exigibles bajo el imperio de la LTE. Esta materia — que puede significar desestimar un recurso por la vía formal sin entrar a conocer siquiera el fondo del asunto- es la que motiva la revisión de una de las últimas decisiones adoptadas por la Corte Suprema sobre el particular.

\section{La controversia: Cogan v/s Corfo}

El 20 de junio de 2014, ante el $14^{\circ}$ Juzgado Civil de Santiago, bajo el rol N¹2.255-2014, "Cogan Grupo Norte S.A." (Cogan) entabló una demanda de restitución e indemnización de perjuicios en contra de la "Corporación de Fomento de la Producción" (Corfo) y del "Comité InnovaChile" (Innovachile) por la suma de \$39.795.698 más 99 UF por concepto de retención de dineros, en función de un contrato de servicios de aseo.

Vencido el período probatorio de este juicio ordinario, la causa fue archivada. Una vez desarchivada, Corfo promovió un incidente de abandono del procedimiento que, por resolución de 24 de diciembre de 2018, fue rechazado. La parte demandada apeló y la Corte de Apelaciones Santiago, por sentencia de 8 de octubre de 2019, revocó la decisión de $1^{\text {a }}$ instancia, acogiendo el incidente de abandono del procedimiento, con costas.

Cogan interpuso un recurso de casación en el fondo que fue concedido por resolución dictada el 6 de noviembre de 2019. El 21 de noviembre de 2019, la Corte de Apelaciones de Santiago tuvo por desistido 
el recurso, en atención a que el recurrente no dio cumplimiento a la carga procesal establecida en los artículos 197 y 776 del Código de Procedimiento Civil vigente antes de la LTE, esto es, depositar fondos suficientes para la confección de las compulsas2.

El 20 de diciembre de 2019, tras una fallida reposición, Cogan interpuso un nuevo recurso de casación en el fondo, dirigido a anular el referido desistimiento. El 13 de febrero de 2020, la Tercera Sala de la Corte Suprema anuló de oficio todo lo obrado hasta la fecha en que se declaró el desistimiento (Sentencia Cogan, causa rol: 20988-2020) y ordenó a la Corte de Santiago dar curso progresivo al primitivo recurso de casación en el fondo orientado — se recuerda - a rebatir el abandono del procedimiento decretado en 2a instancia. Aquel fallo pronunciado en el verano de 2020 - que aplicó las normas de la LTE a una causa de aquellas denominadas "antiguas" iniciada en 2014 - es el que motiva las notas que siguen a continuación.

\section{Puntos críticos de la Sentencia Cogan}

La sentencia en análisis no se ajusta fielmente a las exigencias de la irrupción de la LTE y así: i) se apartó de la letra y espíritu de las disposiciones transitorias de la LTE; ii) fijó como hito temporal para determinar su aplicación la fecha de la resolución que declara el desistimiento del recurso, en vez de la fecha de inicio de la causa; iii) infringió las normas de interpretación de la ley; y iv) erró al establecer que el único objetivo de la LTE era uniformar la tramitación de las causas bajo un sistema digital.

\section{Incidencia de las disposiciones transitorias}

La Sentencia Cogan resolvió que respecto de una "causa antigua" no resulta exigible el trámite de consignar fondos suficientes para la confección de las compulsas y tampoco el consecuente desistimiento, arguyendo que la LTE tiene el carácter de una ley procesal y que rige in actum, conforme al artículo 24 de la Ley sobre Efecto Retroactivo de las Leyes (Cogan Grupo Norte S.A. con Corfo y otro, 2020, considerando $2^{\circ}$ ).

Este razonamiento soslaya la existencia de las disposiciones transitorias de la LTE y su extensión, cuestión trascendental porque, como lo expone el profesor Carlos Ducci (1994), con la entrada en vigor de una nueva ley surgen conflictos que es necesario regular, toda vez que aquella "se encuentra con situaciones constituidas, con derechos adquiridos, con expectativas desarrolladas en un sistema legal que se deroga y que ella pasa a regular en forma distinta" (p. 59). Luego, para dilucidar estos conflictos, prosigue este eximio jurista, sosteniendo que la "primera solución la constituyen las disposiciones transitorias de las leyes (...) que, por lo general, están destinadas precisamente a solucionar dichos problemas” (p. 59).

En el mismo orden de ideas, la Corte Suprema ha declarado que mediante aquellas

el legislador previene los conflictos entre la ley antigua y la nueva (...) es necesario comprobar si existen en la nueva ley las normas o disposiciones transitorias y sólo en ausencia de ellas, o si las que se han dictado presentan vacíos, corresponde acudir a las reglas de dicha Ley sobre Efecto Retroactivo. (Eduardo Chamy y Compañia Limitada con Fisco de Chile y otro, 2014).

Sobre la voz desistimiento empleada por el Código de Procedimiento Civil, la doctrina ha señalado que aquella no es adecuada porque, en rigor, no existe un acto voluntario de la parte, sino más bien una sanción ordenada por el legislador (Núńez y Pérez Ragone, 2015, p. 175). 
La Sentencia Cogan ignoró entonces que el artículo $1^{\circ}$ transitorio de la LTE dispuso que en Santiago dicha ley entraría en vigencia un año después de su publicación, esto es, el 18 de diciembre de 2015. Tampoco prestó atención a que el artículo $2^{\circ}$ transitorio de la LTE, ordenó que "las disposiciones de esta ley solo se aplicarán a las causas iniciadas con posterioridad a su entrada en vigencia” (Ley $\mathrm{N}^{\circ} 20.886,2015$.), o sea, a partir del 18 de diciembre de 2016.

Por cierto, tampoco aludió al Auto Acordado contenido en el Acta $N^{\circ} 37-2016$ (2016) de la Corte Suprema (hoy derogado), cuyo artículo $1^{\circ}$ mandató en su momento que la tramitación electrónica se aplicaba respecto de las causas "iniciadas con posterioridad a la entrada en vigencia de la Ley $\mathrm{N}^{\circ} 20.886$ ". Frase que el artículo $1^{\circ}$ del texto refundido contenido en el Auto Acordado del Acta No 85-2019 (2019) de la Corte Suprema mantuvo y que ahondó al establecer que la LTE rige "desde el ingreso [virtual] de la causa en el Poder Judicial". Todavía más, la Sentencia Cogan soslayó el artículo $3^{\circ}$ transitorio del Auto Acordado del Acta N 71-2016 (2016) de la Corte Suprema, según el cual "en los juzgados con competencia civil se podrá utilizar la Oficina Judicial Virtual para el ingreso de escritos y documentos en las causas iniciadas con anterioridad a la entrada en vigencia de la Ley $\mathrm{N}^{\circ} 20.886$ ”.

\section{Hito temporal relevante}

En este marco conceptual, el fallo en comento también yerra al fijar como hito procesal para la aplicación de la LTE la fecha de la resolución que declara el desistimiento y no la fecha de inicio de una causa, fundamentalmente porque no existe norma alguna que le atribuya efectos procesales a la primera fecha. Entonces, como el juicio en examen se inició dos años antes de la entrada en vigencia de la LTE para Santiago, procedía declarar el desistimiento del recurso de casación en el fondo. Esta ha sido la posición de la Primera Sala de la Corte Suprema que, en un fallo de 3 de julio de 2020, ingreso $N^{\circ} 11.454-2019$, coligió que

la causa en que incide el presente arbitrio se inició en el mes de agosto de 2016, con anterioridad a la entrada en vigencia de la Ley $\mathrm{N}^{\circ} 20.886$ (...) por lo que conforme a lo dispuesto en el referido artículo segundo transitorio el recurrente debió cumplir con la carga económica de consignar dinero suficiente para compulsar o fotocopiar el expediente o las piezas pertinentes. (Constructora Consultora Elorza Ltda. con Ebco S.A., 2020, considerando $3^{\circ}$ ).

Además, esta construcción jurisprudencial conduce a que dicha normativa jamás podría aplicarse a una "causa antigua", pues la providencia que decreta un desistimiento siempre será dictada, por lógica temporal, después de la entrada en vigencia de la LTE, transformándola en letra muerta.

En cambio, la Sentencia Cogan altera este razonamiento lógico, introduciendo como hito para definir la aplicación de la LTE no el inicio de la causa, sino la resolución que declaró desistido el recurso, afirmando que "a la fecha del pronunciamiento de la resolución que declara desistido el recurso de casación (...) razón por la que no resultaba procedente que el tribunal de alzada exigiera su cumplimiento" (Cogan Grupo Norte S.A. con Corfo y otro, 2020, considerando $6^{\circ}$ ). Pero esta reflexión se opone al lenguaje literal del artículo $2^{\circ}$ transitorio de la LTE, del artículo $3^{\circ}$ transitorio del Auto Acordado $N^{\circ} 71-2016$ y del artículo $1^{\circ}$ del Auto Acordado $N^{\circ}$ 85-2019, que fijan como hito decisorio el inicio de una causa y no otra variable.

Sobre el particular, resulta ilustrativa la opinión del profesor Gonzalo Cortez (2016), en cuanto a que

de acuerdo a la disposición transitoria, esta ley solo se aplica a las causas iniciadas con posterioridad a su entrada en vigencia y las causas se entienden iniciadas desde la fecha de presentación de la demanda 
o medida prejudicial, según corresponda. Esto significa que todas aquellas causas iniciadas (...) estarán gobernadas por las disposiciones de la antigua normativa, por lo que los apelantes y recurrentes de casación seguirán sujetos a las cargas procesales que se suprimen con la reforma.

\section{Interpretación de la ley}

Otro error de la Sentencia Cogan consiste en poner en entredicho los artículos 19 y 22 del Código Civil (2013) que, a propósito de la interpretación de la ley, prescriben que cuando el tenor de la misma (la LTE) es claro "no se desatenderá su tenor literal" y que los pasajes obscuros de una ley "pueden ser ilustrados por medio de otras leyes" (analógicamente los Auto Acordados). En este sentido, parece más acorde al tenor y espíritu de la LTE, la aludida sentencia de la Primera Sala de la Corte Suprema, para la cual

de acuerdo al artículo 19 del Código Civil (...) el artículo segundo transitorio en análisis es claro y perentorio al momento de fijar la aplicación de la Ley de Tramitación Electrónica solo a las causas iniciadas con posterioridad a su entrada en vigencia, sin hacer distinción alguna en cuanto a normas de tramitación propiamente tales y cargas procesales, por lo que no resulta procedente, so pretexto de un análisis interpretativo, alterar el alcance de dicha disposición legal efectuando un distingo que no contempla a fin de ajustarla a las pretensiones del recurrente. (Constructora Consultora Elorza Ltda. con Ebco S.A., 2020, considerando $5^{\circ}$ ).

La Historia de la Ley $\mathrm{N}^{\circ} 20.886$ refleja el auténtico espíritu del legislador en orden a que solo las "causas nuevas" quedarían sometidas a las normas de la LTE. En ella se lee, por ejemplo, que el entonces presidente de la Asociación Nacional de Magistrados, Álvaro Flores, señaló que "la reforma debería contemplar un sistema para la tramitación de las causas pendientes que parta con juzgados reformados y otros del procedimiento antiguo y luego establecer vías para afinar los procesos pendientes" (Biblioteca del Congreso Nacional, 2015, p. 31). Igualmente, en el Oficio $N^{\circ} 84-2015$ remitido por la Corte Suprema al Senado, aquella opinó que

las disposiciones de la ley en comento sólo se aplicarán a las causas iniciadas con posterioridad a su entrada en vigencia, aclarando, contrario sensu, que las causas iniciadas con anterioridad a ese hito se seguirán rigiendo por las normas previas. Además, para evitar yerros interpretativos, se aclara que las causas se entenderán iniciadas desde la fecha de presentación de la demanda o medida prejudicial respectiva a distribución de causas o del tribunal de turno. Así se evitarán conflictos respecto de la aplicabilidad de la ley. (Biblioteca del Congreso Nacional, 2015, p. 56).

En suma, tanto la LTE como los Autos Acordados, en su letra y espíritu, demuestran que solo las causas posteriores a la LTE quedaban eximidas de las clásicas sanciones procesales y no las anteriores.

\section{7. ¿Objeto único de la LTE?}

La Sentencia Cogan postula que los alcances del artículo $2^{\circ}$ transitorio son limitados, pues

únicamente se refiere al respaldo material constituido por el expediente físico que ahora pasó a ser electrónico (...) la tramitación electrónica (...) involucró un cambio esencial relacionado con la materialidad del expediente, el que se elimina (...) para realizar la transición, se decidió que las causas anteriores a la vigencia de la ley, que ya contaban con un expediente material, podrían seguir tramitándose de aquel modo. (considerando $7^{\circ}$ ). 
Y remachó su análisis expresando que aquel sería el "único objeto" del artículo $2^{\circ}$ transitorio al ser "una norma excepcionalísima, que debe ser interpretada en armonía con la naturaleza de la ley procesal y con la expresa disposición de vigencia consagrada en el artículo primero transitorio antes referido" (considerando $7^{\circ}$ ). Pero resulta que el artículo segundo transitorio de la LTE ordena que sus normas solo se aplican a las causas iniciadas con posterioridad a su entrada en vigencia. La expresión "solo", sinónimo de "únicamente" o "exclusivamente", revela que la exención de las cargas procesales del sistema recursivo civil — deserción, desistimiento, prescripción - está restringida a los juicios posteriores a la LTE y no aplica a todos los litigios civiles que conocen nuestros tribunales, siendo erróneo prescindir de la época de inicio de cada causa.

Por otro lado, el eje de esta reforma se tradujo en implementar un respaldo digital de los expedientes, pero esto no significa que todos transiten al formato electrónico. En realidad, el propósito del legislador (también de la Corte Suprema al dictar los Auto Acordados de rigor) fue establecer un sistema dual: uno para las causas iniciadas antes de la LTE - que continúan manteniendo un expediente material donde las sanciones siguen en pie- y otro para las causas iniciadas después de la LTE, bajo la forma de carpetas electrónicas en la Oficina Judicial Virtual, donde aquellas sanciones fueron eliminadas.

En este sentido, la Corte Suprema ha corroborado el criterio que se viene proponiendo, en juicios en los que no existen expedientes electrónicos y sí una tramitación material, tal cual ocurre con las "causas antiguas". Por ejemplo, vía recurso de queja, el 14 de abril de 2020, ingreso № 30.549-2020, la Corte Suprema hizo suyo el argumento de que en materia de Policía Local aún rige la carga de hacerse parte, existiendo un expediente único, declarando así la respectiva deserción (Vidal con Urbina, 2020). En otro caso arbitral, ingreso $\mathrm{N}^{\circ} 14.803-2018$, antes había zanjado expresamente que la LTE se funda "en una condición material, como es la capacidad de digitalización y manejo de un soporte electrónico", de manera que la tramitación física de un caso "justifica la ultraactividad de las antiguas disposiciones del Código de Procedimiento Civil, incluyendo la deserción de los recursos" (Sociedad Inversiones Lausen con Morales, 2018, considerando $4^{\circ}$ ). Ciertamente, donde existe la misma razón (soporte material) debe aplicarse la misma disposición (sanción procesal).

Por otro lado, estas distinciones nos reconducen al concepto de igualdad que la Constitución Política reconoce en el $\mathrm{N}^{\circ} 3$ de su artículo 19 como un derecho, asegurando a todas las personas la igual protección de la ley en el ejercicio de sus derechos, bajo un procedimiento racional y justo. Como muchos tópicos del derecho, existen dos visiones a contraponer en relación con la distinción trazada por la LTE. Por una parte, podría aventurarse que imponer dos sistemas paralelos, uno estableciendo sanciones procesales y otro libre de ellas, es arbitrariamente desigual porque perjudica a aquellos litigantes de las "causas antiguas"; y, por otra parte, sostenerse que existen razones plausibles para promover dicha desigualdad. En este punto, me inclino por la segunda alternativa.

No existe un problema de arbitrariedad, porque las sanciones procesales se aplican a un grupo que se encuentra en la misma situación, esto es, causas iniciadas con anterioridad a la LTE, fórmula coincidente con "la visión tradicional de la igualdad [que] se construye sobre la mencionada fórmula aristotélica de tratar igual a los iguales (personas/casos) y desigual a los desiguales" (Díaz de Valdés, 2015, p. 319). Además, porque el artículo $2^{\circ}$ transitorio de la LTE resuelve expresamente los problemas de entrada en vigencia de la nueva ley procesal.

Como lo hizo un particular en el marco de un requerimiento de inaplicabilidad por inconstitucionalidad, ingresado al Tribunal Constitucional bajo el rol No 5.055/18/INA a mediados de 2018 - respecto de los artículos 200, 201 y 779 del Código de Procedimiento Civil y del artículo $2^{\circ}$ transitorio de la LTE—, podría argüirse que más allá del tiempo de inicio de la causa, no hay ninguna diferencia entre el recurrente 
anterior a la ley y el que interpone un recurso con posterioridad o que ambos recurrentes podrían presentar un recurso el mismo día y quedar sometidos a regímenes diferentes ${ }^{3}$.

Ambas aserciones son insuficientes, porque precisamente las disposiciones transitorias resuelven este dilema y permiten que existan distintas reglas para situaciones diferentes, situación de usual ocurrencia en varias sedes, por ejemplo, tributaria o de libre competencia.

Así, el legislador separó expresamente aguas entre las "causas antiguas" y las "causas nuevas", asignó un soporte de tramitación específico para cada cual y eximió explícitamente de las cargas procesales solo a las causas posteriores a la LTE.

La Historia de la Ley $N^{\circ} 20.886$ ratifica que el Congreso Nacional siempre tuvo el espíritu de distinguir entre ambas clases de procesos en función del límite temporal sin que nadie planteara algún viso de desigualdad. Por ejemplo, el senador Araya "consideró recomendable que el nuevo sistema parta de cero, sólo con las nuevas demandas y que la instrucción de los procesos antiguos siga sometiéndose a las reglas anteriores, hasta el total término de su sustanciación" (Biblioteca del Congreso Nacional, 2015, p. 29); y el presidente de la Comisión de Constitución, senador Harboe, destacó que "el nuevo sistema digital que se propone debería implementarse sólo respecto de las causas nuevas, agregando que sería adecuado analizar el tratamiento de los procesos antiguos y su hipotética digitalización en el contexto de la discusión del nuevo proceso civil" (p. 30). Luego, no se advierte una desigualdad arbitraria o que cause perjuicios a un grupo de causas en desmedro de otro y, a la larga, la aplicación de las sanciones procesales en comento dependerá de la negligencia de aquel litigante que no cumpla con la ritualidad del proceso.

Por lo demás, si el propósito de la LTE hubiese sido que todas las miles de causas que se tramitan ante los tribunales y Cortes quedaran eximidas de las cargas procesales ya referidas, como un solo grupo o categoría, entonces lo habría reglado expresamente o algún indicio constaría en la Historia de la Ley $\mathrm{N}^{\circ}$ 20.886 y, en cambio, no se habría detenido en aclarar en el artículo $2^{\circ}$ transitorio, por ejemplo, que para los efectos de esta ley una causa se entiende iniciada "desde la fecha de presentación de la demanda o medida prejudicial” (Ley $\left.\mathrm{N}^{\circ} 20.886,2015\right)$.

\section{Conclusión}

La LTE impulsó un cambio radical, estableciendo que la tramitación de los litigios civiles pasaría a implementarse bajo un esquema digital de carpetas electrónicas. Al mismo tiempo, derogó las sanciones procesales de deserción, desistimiento y prescripción de los recursos, así como las cargas procesales asociadas a aquellas; y en su artículo $2^{\circ}$ transitorio ordenó que sus disposiciones solo se aplicarían a las causas iniciadas con posterioridad a su entrada en vigencia, esto es, el 18 de diciembre de 2016 para Santiago, fijando como hito de inicio de una causa la fecha de presentación de la demanda o de la medida prejudicial de rigor.

La sentencia de la Tercera Sala de la Corte Suprema de 13 de abril de 2020 decidió que respecto de una causa iniciada el 2014, el desistimiento por no consignar las compulsas de un recurso de casación en el fondo no resulta aplicable. Tal decisión resulta discutible, porque las "causas antiguas" continúan regidas por las reglas del Código de Procedimiento Civil previas a la LTE, incluyendo aquella que consagra el

El Tribunal Constitucional declaró inadmisible este requerimiento. A la fecha se han ingresado similares requerimientos sobre las normas relativas al desistimiento y la deserción, pero todos han corrido la misma suerte. Ver roles $N^{\circ}$ 6.763/19/INA y 6.965/19-INA. 
desistimiento de un recurso por no pago de compulsas, en función de otros fallos de la Corte Suprema, la Historia de la Ley $\mathrm{N}^{\circ} 20.886$, la doctrina y normativa procesal civil. Lo anterior, fundamentalmente porque la Sentencia Cogan prescindió de la letra de las disposiciones transitorias de la LTE, desconoció que el único hito relevante para determinar la aplicación de la LTE a una causa es su fecha de inicio, se apartó de las normas de interpretación de la ley del Código Civil y razonó erróneamente que el único objeto de la LTE diría relación con la materialidad del expediente.

\section{Bibliografía citada}

Biblioteca del Congreso Nacional (2015): Historia de la Ley $N^{\circ}$ 20.886. Disponible en: https://www.bcn. cl/historiadelaley/nc/historia-de-la-ley/468. [Fecha de consulta: 22/01/2021].

Cortez Matcovich, Gonzalo (2017): "Vigencia temporal de la Ley N² 20.886 sobre tramitación digital de los procedimientos judiciales", El Mercurio legal, 18 de enero. Disponible en: https://www. elmercurio.com/Legal/Noticias/Opinion/2017/01/18/Vigencia-temporal-de-la-ley-N-20886sobre-tramitacion-digital-de-los-procedimientos-judiciales.aspx [Fecha de consulta: 22/01/2021].

Díaz de Valdés, José Manuel (2015): “¿Qué clase de igualdad reconoce el Tribunal Constitucional?”, Revista Ius et Praxis, No 2: pp. 317-372.

Ducci Claro, Carlos (1994): Derecho Civil Parte General (Santiago, Editorial Jurídica de Chile, tercera edición).

Núñez Ojeda, Raúl y Pérez Ragone, Álvaro (2015): Manual de Derecho Procesal Civil: Los medios de impugnación (Santiago, Thomson Reuters).

\section{Normas citadas}

Código Civil de Chile, actualizado al 04/01/2013.

Ley N ${ }^{\circ} 20.886$ (18/12/2015) Modifica el Código de Procedimiento Civil, para establecer la tramitación digital de los procedimientos judiciales.

Acta $N^{\circ} 37-2016$ (22/04/2016) Auto Acordado para la aplicación en el Poder Judicial de la Ley $\mathrm{N}^{\circ}$ 20.886, que modifica el Código de Procedimiento Civil, para establecer la tramitación digital de los procedimientos judiciales.

Acta $N^{\circ}$ 71-2016 (08/07/2016) Auto Acordado que regula el funcionamiento de tribunales que tramitan electrónicamente.

Acta $\mathrm{N}^{\circ}$ 85-2019 (14/06/2019) Texto refundido del auto acordado para la aplicación en el Poder Judicial de la Ley No 20.886, que establece la tramitación digital de los procedimientos judiciales.

\section{Jurisprudencia citada}

Cogan Grupo Norte S.A. con Corfo y otro (2020): Corte Suprema, 13 de abril de 2020 (recurso de casación en el fondo).

Constructora Consultora Elorza Ltda. con Ebco S.A. (2020): Corte Suprema, 3 de julio de 2020 (recurso de casación en el fondo).

Eduardo Chamy y Compañia Limitada con Fisco de Chile y otro (2014): Corte Suprema, 6 de enero de 2014 (recurso de casación en el fondo).

Sociedad Inversiones Lausen con Morales (2018): Corte Suprema, 23 de octubre de 2018 (recurso de casación en el fondo).

Vidal con Urbina (2020): Corte Suprema, 14 de abril de 2020 (recurso de queja). 